\title{
DEMOSTENOCRACIA Y PUEBLECÍA
}

Julián Meza*

Creo que confundes las cosas -dijo Demades. Democracia y demostenocracia.

Gilbert Haefs, Alejandro Magno.

Siempre dicen que van a mejorar las cosas, pero ya no me lo creo.

Taghrid Choucair, libanesa de 18 años.

Pese a cuanto se pueda decir en sentido inverso, las modernas democracias no viven su mejor época. Ni siquiera pasan por un buen momento. En todos los países democráticos se perciben malestares de los más diversos signos, cunden las manifestaciones de inconformidad y hay protestas cuya causa no es, ciertamente, la democracia, sino su mal funcionamiento, y de ahí la eclosión de variados comportamientos antidemocráticos. Son consecuencia de los atentados que con reiterada frecuencia perpetran contra los valores democráticos sus propios promotores, partidarios y defensores, que a menudo son, al mismo tiempo, sus principales detractores y, paradójicamente, sus mayores beneficiados.

Ejemplos incuestionables de la institucional antidemocracia son el actual presidente de los USA, George Bush, y no pocos funcionarios y políticos de su entorno inmediato.

* Departamento Académico de Estudios Generales, ITAM. 
Es por lo menos una señal de grave opacidad en el desempeño de los políticos franceses el hecho de que la socialista Segolème Royal proponga la creación de jurados populares integrados por ciudadanos elegidos mediante sorteo para supervisar el cumplimiento de los programas de los cargos elegidos. Confirma la pertinencia de esta propuesta el hecho de que sus pares, los barones del Partido Socialista francés, sean los primeros en dar muestras de irritación ante la sola sospecha de que no haya transparencia en el quehacer de los representantes elegidos mediante sufragio.

Día tras día llueven las acusaciones de participar escandalosamente en la especulación inmobiliaria sobre legiones de funcionarios públicos afiliados a los dos principales partidos políticos españoles: el socialista y el popular. Y no es ésta la única modalidad de la corrupción en este país.

El primer ministro de Inglaterra es objeto de diversas críticas en el interior de su propio partido y obligado a anticipar elecciones debido a su pésima gestión en asuntos internos y a su peor desempeño en política exterior, supeditada a las arbitrarias decisiones de Washington a raíz del $11 \mathrm{~S}$.

El canciller alemán es derrotado electoralmente por atentar contra las instituciones sociales que quedan del maltrecho estado de bienestar tan rentable en tiempos de la guerra fría.

La democracia rusa está presidida por un plutócrata, expolicía del KGB, a cuyo gobierno parecen no afectar persecuciones, encarcelamientos y asesinatos que no sólo recuerdan los métodos expeditivos de los jerarcas soviéticos, sino los de los antiguos zares. Una de las principales bases de apoyo del presidente de Rusia es el ultranacionalismo que le permite actuar impunemente contra chechenos y georgianos.

Es tan complaciente la mirada liberal de Occidente, entusiasmada con la relativa apertura de China al comercio exterior, que no puede menos que irritar por su ceguera ante las constantes violaciones a los derechos ciudadanos en las ciénagas del totalitarismo heredado de Mao.

Los castigos impuestos a los demostenocratas son puntos a favor de la democracia, pero no borran ni impiden la reiteración de sus tropelías, ni frenan el ascenso antidemocrático de la pueblocracia. 
Cansado de soportar las violaciones de los políticos a las instituciones democráticas, el electorado pierde la brújula y se entrega, presa del miedo (al desempleo, a la inmigración, a la inseguridad, al terrorismo) a gentuza de todos los pelajes, cuya vocación democrática es sólo coyuntural. O, por ser más precisos, electoral. Es escandalosa la multiplicación de partidos de extrema derecha en buena parte del planeta: uno en Eslovenia, Serbia e Israel (en donde el socialdemócrata Olmert comparte su gobierno con el partido ultranacionalista), dos en Suecia, Ucrania, Eslovaquia, Francia y Polonia, tres en Inglaterra, Suiza, Eslovenia, Turquía, Finlandia, Grecia, Austria, Bélgica y Dinamarca, cuatro en Holanda y Alemania, ocho en Rusia, y los partidos que no son abiertamente de ultraderecha lo son por herencia y vocación, como el Partido Popular (nieto de Franco e hijo de Fraga) en España. Es por lo menos curioso que tanto en Francia como en España dos de los principales partidos políticos se autodesignen populares. En Francia la Unión por un Movimiento Popular (UMP) y en España el Partido Popular (PP) me llevan a preguntar: ¿qué querrá decir en ambos casos la acepción 'popular'? ¿A qué pueblo o clase de pueblo remitirá? Obviamente, no a los hijos de inmigrantes argelinos o marroquíes, ni a los seculares marginados de ambos países. ¿Acaso habrán naufragado estos demostenocratas en el piélago de la populocracia?

En los USA no hay partidos de ultraderecha (declarados), pero sí variopintos grupos racistas y aun terroristas que actúan fuera de la ley y no parecen inquietar a un estado gobernado por plutócratas ocupados en combatir el peligro exterior con métodos que van del ejercicio cotidiano de la mentira a la violencia (incluida la maquillada legalización de la tortura) sin fronteras.

Esta situación no prefigura nada bueno y, no sin temor, recuerda las elecciones que en 1933 dieron el poder a los nacionalsocialistas en Alemania y que sólo preocuparon a las rarísimas mentes lúcidas de la época, como Hannah Arendt. 


\section{II}

El caos que prevalece no es una novedad si se recuerda que las grandes (y las pequeñas) democracias del pasado tarde o temprano se agotaron y se desplomaron, con mayor o menor estrépito, debido a que quienes se habían encomendado a la tarea de preservarlas, las descuidaron o de plano atentaron contra ellas. No resulta inútil evocar los avatares de la democracia griega. La de Solón y Dracón fue suprimida por Pisístrato en 560 antes de nuestra era y restablecida por Clístenes 46 años después. La politeia griega se extinguió paulatinamente en épocas posteriores a la de Pericles por obra de demagogos como Demóstenes. En este punto no está por demás recordar que Aristóteles pensaba que la democracia era una degeneración de la politeia o república (gobierno de muchos). La república romana cayó en un estado de postración después del asesinato de César. El progresivo crecimiento del estado hundió a las ciudades-estado en Italia, a las ciudades libres en Suiza y Flandes y a las que formaban parte de la Liga Hanseática hacia el final de la baja Edad Media.

Más cerca de nosotros en el tiempo, ha habido países en donde la democracia fue desterrada durante períodos más o menos largos. Los totalitarismos y las dictaduras en la Europa del siglo XX impidieron el advenimiento de la democracia (Rusia) o la proscribieron durante años (Alemania, Francia, Grecia) y aun durante muchas décadas (Italia, España, Portugal). Con mayor frecuencia ocurrió así en la mayoría de los países hispanoamericanos. En ciertos casos mediante violentos golpes de estado (Guatemala, Bolivia, Perú, Brasil, Chile, Argentina, Uruguay). En otros casos de manera menos evidente, como en México, en donde se instaló una peculiar dictadura a raíz del brevísimo período democrático que sucedió a la hoy endulzada dictadura de Porfirio Díaz. 


\section{III}

Tras su triunfo, una de las facciones armadas (la de los sonorenses) que convulsionaron el país durante años, instaló con cierta celeridad lo que Mario Vargas Llosa llamó, muy acertadamente, 'la dictadura perfecta', y difirió la democracia en México a las calendas griegas. En otras palabras, impuso el simulacro democrático que sirvió para enmascarar la dictadura de un partido único, cuyo soporte fundamental fue la corporativización de la sociedad (como ocurrió en la Italia de Mussolini, en la URSS y en la Alemania nazi).

Hasta hace poco se creyó (y todavía hacen cola los cándidos creyentes frente al altar de las veneradas instituciones democráticas) que la derrota electoral de ese partido único (más longevo que el partido comunista de la URSS) iba a eliminar (tal vez por arte de magia) los usos y costumbres propios de su peculiar autoritarismo. Por desgracia, no ha sido así, y no podía ser de otra manera. Sus prácticas habituales prevalecen dentro y fuera de las instituciones que él mismo creó con el propósito de forjarse una apariencia democrática. Durante sus más de setenta años de hegemonía, el partido único operó mediante la ficción de instituciones propias de las democracias modernas: una república federal (ajena al federalismo) gobernada por tres poderes: ejecutivo, legislativo y judicial. El ejecutivo era despóticamente omnímodo y pretendía ser omnisciente. El legislativo se mantuvo servil y egoístamente sometido a los egotistas dictados del primero. La justicia fue (y es) tributaria de los poderosos y humilló a los débiles, en particular cuando se atrevían (y se atreven) a protestar. Los gobernadores y los congresos de los estados eran (y son) caciquiles y estuvieron subordinados a las polimanías del poder ejecutivo. Los presidentes municipales proliferaron en los bajos fondos del autoritarismo. Se crearon sindicatos cuyos inmortales dirigentes fueron utilizados por los gobernantes para controlar a sus agremiados. La libertad de expresión fue mero artículo de fe, pues siempre se ejercieron sobre ella el control 
y la censura. La escuela pública tuvo (y tiene) algo de pública, pero prácticamente nada de escuela.

Tras consolidar su hegemonía, el partido único toleró la existencia de partidos de oposición, que funcionaron como figurantes hasta el momento en que decidió concederles una representación simbólica en la cámara de diputados y en destartalados municipios. La reforma electoral que él mismo promovió dio origen a una institución que, paradójicamente, presidiría su derrota en las urnas el año 2000: el Instituto Federal Electoral. Se creyó entonces, y se sigue creyendo, que se iniciaba así la transición democrática en México (recurriendo a una arbitraria analogía con la transición democrática en España).

\section{IV}

Es verdad que México cuenta con casi todas las instituciones propias de un régimen democrático, pero su funcionamiento atenta a menudo contra este mismo régimen. ¿Por qué? Por la sencilla razón de que no se han dejado atrás muchas de las prácticas antidemocráticas que hicieron posible el mantenimiento del régimen autoritario. La más extendida de todas es la corrupción (que impregna a buena parte de la sociedad y que se agudizó durante las últimas décadas de dominación del partido único), pero no es la única. Junto con ésta prevalecen la arbitrariedad, la irresponsabilidad, el abuso y la arrogancia del poder, la mentira, la injusticia, los atentados contra los derechos ciudadanos, la inseguridad en diversos ámbitos, la discriminación étnica y aun religiosa (no ser católico es algo más que un pecado a los ojos de la jerarquía eclesiástica y de los arciprestes que nos gobiernan), la inequitativa distribución del ingreso, la delincuencia instalada en el interior de las instituciones policíacas, militares, carcelarias y jurídicas, a menudo amafiadas con el crimen organizado al menudeo (pequeños delincuentes) o al mayoreo (narcotraficantes). 


\section{V}

Hoy en México hay democracia, pero su fragilidad es tan grande que su porvenir es por lo menos incierto. La única manera de fortalecerla consistiría en desterrar paulatinamente tanto los vicios heredados del antiguo régimen autoritario como los que ya se han introducido en su breve existencia.

Una de las piezas más robustas y temibles del incontinente ajedrez autoritario fue el poder ejecutivo. Hoy este poder no se ha liberado de sus ataduras a los vicios del pasado: abusos, arbitrariedad, irresponsabilidad, arrogancia, mentira, que se han incrementado con una enfática disponibilidad para el tartufismo multimedia. Y a la vez es débil frente a un poder legislativo representado por demostenocratas y tribunos entretenidos en darse baños de pueblecía o populocracia. Más aún: son escasos los ciudadanos que respetan al presidente porque lo perciben como una especie de humorista involuntario que desata la hilaridad cada vez que abre la boca.

El poder judicial no ha modificado un ápice sus comportamientos. Jueces varios y variadas policías están hipotecados a los gobernantes actuales o a los poderes paralelos. Excepto cuando deciden operar por cuenta propia como asaltantes, secuestradores, asesinos o cómplices de todos éstos.

Los gobernadores de los estados se han convertido en una especie de casta sacerdotal intocable (que no remite a los parias de la India). El poder ejecutivo los trata como brahamanes porque eventualmente pueden ser útiles en sus irreligiosos oficios. Éste es el caso de los gobernadores de Puebla y de Oaxaca en épocas recientes. En tiempos del poder presidencial omnipotente (que no añoro) los gobernadores eran despedidos cuando afeaban la imagen del príncipe.

Los legisladores de los estados ya no acatan órdenes. Ahora son atracadores por cuenta propia.

Los presidentes municipales surgen a borbotones de las alcantarillas de la frágil democracia. 
Los dirigentes sindicales son los mismos de antaño o se han visto reemplazados por otros que son sus sosias.

En México hay libertad de expresión, pero su ejercicio se limita al insulto o a la complacencia.

La escuela pública sigue siendo pública, pero todavía no es escuela. Sujetos extraídos de las profundidades de la época cenozoica graznan desde las cimas de la pedagogía institucional. Todavía esperan ser diseñados verdaderos proyectos educativos mientras maestros al borde de un ataque de analfabetismo integral obligan a sus alumnos a recitar el catecismo único y obligatorio de la enseñanza básica a la intermedia. El ejercicio de la reflexión y de la crítica está desterrado de la enseñanza. No se vislumbran en este horizonte posibilidades de impartir verdadera educación ni, eventualmente, hacer investigación técnica y científica. Y en todos estos aspectos las escuelas privadas no son una alternativa, sino mera reiteración de un pasado escolar en donde impera la mnemotecnia.

Al igual que en tiempos anteriores a la frágil democracia mexicana, pero ahora becados por el Instituto Federal Electoral, los partidos políticos disputan los cargos públicos como botín. Una vez instalados en sus cómodos sillones los representantes de nuestras representativas instituciones democráticas ocupan su tiempo en dormir, pegar alaridos y agotar presupuestos que, al igual que ellos, son cada vez más obesos.

La práctica más común en el pasado fue la corrupción institucionalizada y la que se practicaba al margen de las instituciones. Institucionalizada: estipendios de funcionarios públicos comparables sólo con los ingresos de un jeque. No institucional: el soborno, el peculado, la dilapidación del erario público. Ninguna de estas formas de la corrupción ha desaparecido. Al contrario: se han incrementado, pues los ingresos de estos jeques se han convertido en ganancias propias de un califa. El soborno sigue siendo un modo de vida habitual. El peculado no ha tomado vacaciones. Y la dilapidación del erario público no es una especie en proceso de extinción. 


\section{VI}

¿Cuáles son, pues, las principales características de la frágil democracia mexicana?

Es un lugar común citar a Demóstenes como el gran orador que defendió la democracia ateniense. Rara vez se alude a este demagogo que, movido por su odio a Filipo II de Macedonia, recibió oro de los sátrapas persas, condujo a sus compatriotas a la muerte en inútiles batallas (como la de Queronea) y socavó los fundamentos de la democracia ateniense.

Los políticos de la frágil democracia mexicana son émulos tartamudos del demagogo ateniense. Al igual que éste ejercen su poder como implacables demostenocratas. Para Demóstenes la solución era la guerra contra los macedonios; para nuestros modernos demostenocratas la soluciones son el libre mercado (que no puede ser muy libre en un mundo en donde los países ricos practican el monopolio y el proteccionismo), las privatizaciones e impuestos que pagan en la misma proporción las personas con ingresos medianamente aceptables y los Midas de los negocios. Demóstenes perdió todas las batallas. Nuestros demostenocratas están camino a perder una guerra que parecerían librar aun contra ellos mismos, pero que en realidad apunta a la preservación de la plutocracia, la masmediocracia y la narcocracia que ya gobiernan dentro o fuera de nuestras instituciones. Frente a estos temibles personajes están otros no menos temibles: los tribunos del pueblo, cuyos discursos son grotescas zambullidas en mares de pueblecía o populocracia. Son nuestro peculiares populares, que recuerdan a los que, como Catilina, apostaron por las asambleas del pueblo y contribuyeron a liquidar la antigua república romana. Son aquellos que no podrían escapar a la reflexión de Aristóteles cuando critica la desviación en la que el pueblo suplanta a la ley, bajo el influjo de los demagogos, y da lugar a un despotismo comparable con la tiranía.

¿Qué se puede hacer, entonces, para dar vitalidad a nuestra frágil democracia? 


\section{VII}

En mi opinión, que remite a Aristóteles, la democracia debe ser valorada en función de si cumple o no con fines determinados por el bien de la comunidad y fundados en principios de justicia.

¿Cumplen nuestras instituciones democráticas con estos fines? Me temo que no, pero no por esto hay que desecharlas. Al contrario: hay que encaminarlas a que cumplan con esos fines. Y esta tarea no puede ser (no podría ser) obra de nuestros políticos profesionales, sino de los simples ciudadanos, que deben sustraerse a la atomización y al individualismo politizándose para poder ocuparse de los asuntos públicos sin la complacencia propia de los intelectuales que, enfermos de democratitis, pegan de brincos cuando se señala que nuestras instituciones no cumplen con sus fines y a menudo son ajenas a la justicia.

La democracia no se fortalece con comentarios complacientes cuando en la práctica se atenta contra ella y se minimizan los daños. La democracia moderna es, como lo recordaba con frecuencia Octavio Paz, hija de la crítica, que es uno de los pilares fundamentales de Occidente. No ejercer esta crítica es una forma de complicidad con nuestros demostenocratas y puede abrir el camino a los tribunos de la populocracia o pueblecía.

México, octubre de 2006. 